\title{
Bacterial degradation of poly(trans-1,4-isoprene) (gutta percha)
}

Correspondence

Alexander Steinbüchel

steinbu@uni-muenster.de

Received 14 July 2006

Revised 20 September 2006

Accepted 31 October 2006

\author{
Sören Warneke, ${ }^{1}$ Matthias Arenskötter, ${ }^{1}$ Klaus B. Tenberge ${ }^{2}$ \\ and Alexander Steinbüchel ${ }^{1}$
}

${ }^{1}$ Institut für Molekulare Mikrobiologie und Biotechnologie, Westfälische Wilhelms-Universität Münster, Corrensstrasse 3, D-48149, Germany

${ }^{2}$ Institut für Botanik und Botanischer Garten, Westfälische Wilhelms-Universität Münster, Schlossgarten 3, D-48149, Germany
Gutta percha, the trans-isomer of polyisoprene, is being used for several technical applications due to its resistance to biological degradation. In the past, several attempts to isolate micro-organisms capable of degrading chemically pure poly(trans-1,4-isoprene) have failed. This is the first report on axenic cultures of bacteria capable of degrading gutta percha. From about 100 different habitats and enrichment cultures, six bacterial strains were isolated which utilize synthetic poly(trans-1,4-isoprene) as sole carbon and energy source for growth. All isolates were assigned to the genus Nocardia based on 16S rRNA gene sequences. Four isolates were identified as strains of Nocardia nova (L1b, SH22a, SEI2b and SEII5a), one isolate was identified as a strain of Nocardia jiangxiensis (SM1) and the other as a strain of Nocardia takedensis (WE30). In addition, the type strain of $N$. takedensis obtained from a culture collection (DSM 44801 ${ }^{\top}$ ) was shown to degrade poly(trans-1,4-isoprene). Degradation of poly(trans-1,4-isoprene) by these seven strains was verified in mineralization experiments by determining the release of $\mathrm{CO}_{2}$. All seven strains were also capable of mineralizing poly(cis-1,4-isoprene) and to use this polyisoprenoid as a carbon and energy source for growth. Mineralization of poly(trans-1,4-isoprene) after 80 days varied from $3 \%$ (strain SM1) to $54 \%$ (strain SEI2b) and from $34 \%$ (strain L1b) to $43 \%$ (strain SH22a) for the cis-isomer after 78 days. In contrast, Gordonia polyisoprenivorans strain $\mathrm{VH} 2$, which was previously isolated as a potent poly(cis-1,4-isoprene)-degrading bacterium, was unable to degrade poly(trans-1,4-isoprene). Scanning electron microscopy revealed cavities in solid materials prepared from poly(trans-1,4-isoprene) and also from poly(cis-1,4-isoprene) after incubation with $N$. takedensis strain WE30 or with $N$. nova strain L1b, whereas solid poly(trans-1,4-isoprene) material remained unaffected if incubated with G. polyisoprenivorans strain $\mathrm{VH} 2$ or under sterile conditions.

\section{INTRODUCTION}

Two types of polyisoprenoides, which differ according to their isomerism, are almost exclusively synthesized by many plants: poly(cis-1,4-isoprene) and poly(trans-1,4-isoprene). The cis isomer (natural rubber, NR) is produced by more than 2000 dicotyledonous plants (Backhaus, 1985) and is an industrially important polymer used for many technical applications such as fabrication of automobile tyres. The trans isomer (gutta percha, GP) is synthesized by much

\footnotetext{
Abbreviations: GP, gutta percha; NR, natural rubber.

The GenBank/EMBL/DDBJ accession numbers for the 16S rRNA gene sequences reported in this paper are D0840025 (N. takedensis WE30), DQ840027 ( N. jiangxiensis SM1), D0840026 ( N. nova L1b), D0840028 ( $N$. nova SH22a), D0840029 ( $N$. nova SEI2b) and DQ840030 (N. nova SEll5a).
}

fewer plants and occurs, for example, in South-east Asian trees Palaquium gutta and Eucommia ulmoides, the European shrub Euonymus europaeus and the South American tree Couma macrocarpa. GP is used for several applications due to its resistance to biological degradation. This polymer has been used since the last century as an insulation material for transatlantic telegraph cables, and it is still used for the production of conveyers, golf balls, decoration objects, chewing gum and in dentistry to fill root canals.

First investigations on the biodegradation of NR were carried out in the early 20th century (Söhngen \& Fol, 1914; for a review, see Rose \& Steinbüchel, 2005), but only recently have two genes encoding enzymes capable of poly (cis-1,4isoprene) cleavage been isolated, independently from different bacteria. In the NR-degrading bacterium 
Xanthomonas sp. 35Y, RoxA was identified (Braaz et al., 2004) which acts as a dioxygenase on poly(cis-1,4-isoprene), resulting in the formation of short-chain isoprenoid intermediates. Lcp (Latex-clearing protein) was identified in Streptomyces sp. K30, and the lcp gene restored the wildtype phenotype in a chemically induced rubber-negative mutant of this bacterium lacking the ability to degrade NR as indicated by the absence of haloes if grown on NR latexcontaining agar plates (Rose et al., 2005). Intermediates resulting from cleavage of poly(cis-1,4-isoprene) by actinomycetes harbouring Lcp have been identified as isoprenoids with approximately 20 isoprene units (Ibrahim et al., 2006). Apart from the number of isoprene moieties of the cleavage products, intermediates of poly(cis-1,4-isoprene) degradation produced by RoxA and Lcp exhibit a similar chemical structure, possessing one terminal ketone and one terminal aldehyde functional group. However, RoxA and Lcp share no sequence homologies, indicating two individually evolved enzyme systems for rubber cleavage. So far no proteins homologous to RoxA have been identified in bacteria other than Xanthomonas sp. 35Y, whereas the presence of genes encoding Lcp homologues has been shown in the genomes of several actinomycetes capable of rubber degradation. In Streptomyces sp. K30, two ORFs (oxiA and oxiB), putatively encoding a heterodimeric molybdenumdependent aldehyde dehydrogenase, are located downstream of $l c p$. Recombinant strains of Streptomyces lividans TK23 expressing $l c p$ and oxiBA do not accumulate aldehydes around the colonies if grown on NR latex as was observed for strains expressing only $l c p$. As revealed by transposoninduced rubber-negative mutants of Gordonia polyisoprenivorans, degradation intermediates of poly(cis-1,4-isoprene) enter the central metabolism via $\beta$-oxidation with the involvement of a specific $\alpha$-methylacyl-coenzyme A racemase (Banh et al., 2005).

In contrast to NR degradation, no micro-organisms capable of degrading poly(trans-1,4-isoprene) have been described to date. In addition, only very few studies have been published on microbial degradation of GP. Kupletskaya et al. (1960) tried to demonstrate biodegradability of GP by fermentation studies of Eucommia leaves; however, the micro-organisms isolated were incapable of degrading chemically pure poly(trans-1,4-isoprene). The weight losses of blends of poly(trans-1,4-isoprene) and starch observed by Arvanitoyannis et al. (1998) were solely due to degradation of the starch. So far, cleavage of either isomer of polyisoprene has only been demonstrated in vitro employing enzyme-mediator systems like lipoxygenase/linoleic acid or laccase/1-hydroxybenzotriazole/linoleic acid as radical producers (Enoki et al., 2003). This study aimed to isolate and characterize axenic cultures of poly(trans-1,4-isoprene)degrading bacteria and to compare microbial degradation of GP and NR.

\section{METHODS}

Bacterial strains and growth conditions. Bacterial strains used in this study are listed in Table 1. Cells of G. polyisoprenivorans VH2, Nocardia sp. and Rhodococcus opacus PD630 were cultivated at $30{ }^{\circ} \mathrm{C}$ in Standard I nutrient broth (St-I; Merck), Caso medium (Merck) or mineral salts medium (MSM) as described by Schlegel et al. (1961). The following polyisoprenoides were added as carbon sources to liquid MSM: $0.6 \%$ (w/v) cryomilled synthetic poly(trans1,4-isoprene) with a mean molecular mass of approximately $410 \mathrm{kDa}$ (Aldrich) or $0.6 \%(\mathrm{w} / \mathrm{v})$ milled synthetic poly(cis-1,4-isoprene) with a mean molecular mass of $800 \mathrm{kDa}$ (Aldrich). Synthetic poly(cis-1,4-isoprene) was milled in the presence of inert talcum $\left(3 \mathrm{MgO} .4 \mathrm{SiO}_{2} \cdot \mathrm{H}_{2} \mathrm{O}\right)$ in the ratio $1: 1$ to prevent coagulation of the polymer particles and was added before autoclaving, whereas poly(trans-1,4-isoprene) was frozen in liquid nitrogen before cryomilling in a ZM200 rotation mill (Retsch), yielding particles with grain sizes between $62 \mu \mathrm{m}$ and $1.4 \mathrm{~mm}$. GP was sterilized with $70 \%(\mathrm{v} / \mathrm{v})$ ethanol, added after autoclaving and subsequently evaporated in a vacuum. For mineralization experiments, poly(trans-1,4-isoprene) and poly(cis-1,4-isoprene) with a defined range of grain size was obtained by sieving in an AS200 sieve shaker (Retsch).

Liquid cultures in Erlenmeyer flasks were incubated on a horizontal rotary shaker. Solid media were prepared by the addition of $1.5 \%(\mathrm{w} / \mathrm{v})$ agar. NR latex overlay agar plates, for characterizing the ability to

Table 1. Strains used in this study

\begin{tabular}{|c|c|c|}
\hline Strain & Characteristics/origin & Reference \\
\hline Gordonia polyisoprenivorans $\mathrm{VH} 2$ & NR-degrading wild-type & DSM 44266 \\
\hline Rhodococcus opacus PD630 & Degrades no polyisoprene & DSM 44193 \\
\hline Nocardia takedensis & NR- and GP-degrading wild-type isolated from activated sludge & DSM $44801^{\mathrm{T}}$ \\
\hline Nocardia takedensis WE30 & NR- and GP-degrading wild-type isolated from soil of Amazon rainforest & This study \\
\hline Nocardia nova L1b & $\begin{array}{l}\text { NR- and GP-degrading wild-type isolated from soil of a Euonymus europaeus } \\
\text { population in Lingen, Germany }\end{array}$ & This study \\
\hline Nocardia nova SH22a & NR- and GP-degrading wild-type isolated from a root of Couma macrocarpa (Brazil) & This study \\
\hline Nocardia nova SEI2b & $\begin{array}{l}\text { NR- and GP-degrading wild-type isolated from soil below a Couma macrocarpa } \\
\text { tree (Brazil) }\end{array}$ & This study \\
\hline Nocardia nova SEII5a & $\begin{array}{l}\text { NR- and GP-degrading wild-type isolated from soil below a Couma macrocarpa } \\
\text { tree (Brazil) }\end{array}$ & This study \\
\hline Nocardia jiangxiensis SM1 & NR- and GP-degrading wild-type isolated from latex of Couma macrocarpa (Brazil) & This study \\
\hline
\end{tabular}


produce translucent haloes by degradation of the water-insoluble polymers, were prepared as described previously (Ibrahim et al., 2006); GP latex from the South American tree Couma utilis was applied accordingly.

Enrichment and isolation of GP-degrading bacteria. Soil and plant samples were taken from different habitats of autochthonous Euonymus europaeus populations in Germany and also from different areas with Couma macrocarpa populations in the Amazon rainforest in Brazil. Samples were incubated in $50 \mathrm{ml}$ MSM medium containing $0.6 \% \quad(\mathrm{w} / \mathrm{v})$ cryomilled poly(trans-1,4-isoprene). If growth was macroscopically detected by an increase in turbidity, several strains of the respective cultures were brought to axenic cultures on solid St-I medium. The strains obtained were then individually tested in liquid culture for their capability to degrade synthetic poly(trans-1,4-isoprene). Purity of cultures capable of GP degradation was verified both by smearing on St-I medium and by direct determination of $16 \mathrm{~S}$ rRNA gene sequences (see below).

Taxonomic studies. Gram-staining was performed according to Gerhardt et al. (1994). Bactident oxidase test strips were applied for oxidase testing (Merck). Catalase activity was determined by adding $3 \%(\mathrm{v} / \mathrm{v}) \mathrm{H}_{2} \mathrm{O}_{2}$ to a freshly grown colony. Cleavage of L-alanylnitroanilid was tested by applying Bactident LAAP test strips (Merck).

Isolation of total DNA. A sample $(1.5 \mathrm{ml})$ of a well grown culture in MSM containing poly(trans-1,4-isoprene) was harvested by centrifugation and resuspended in $500 \mu \mathrm{l}$ SET buffer $(75 \mathrm{mM} \mathrm{NaCl}$, $25 \mathrm{mM}$ EDTA, $20 \mathrm{mM}$ Tris/ $\mathrm{HCl}$, pH 7.5) containing $3 \mathrm{mg}$ lysozyme $\mathrm{ml}^{-1}$. After $2 \mathrm{~h}$ incubation at $37^{\circ} \mathrm{C}, 50 \mu \mathrm{l}$ of an SDS solution $\left(100 \mathrm{~g} \mathrm{l}^{-1}\right)$ and $20 \mu \mathrm{l}$ of a proteinase $\mathrm{K}$ solution $\left[20 \mathrm{~g}(1 \mathrm{TE})^{-1}\right.$; TE, $1 \mathrm{mM}$ EDTA and $10 \mathrm{mM}$ Tris/ $\mathrm{HCl}, \mathrm{pH}$ 8.0] were added and mixed gently, followed by another incubation for $2 \mathrm{~h}$ at $55^{\circ} \mathrm{C}$. Subsequently, 0.33 vols of a $5 \mathrm{M} \mathrm{NaCl}$ solution and 1 vol. chloroform were added and mixed gently. After $30 \mathrm{~min}$ incubation at room temperature, the phases were separated by centrifugation and the aqueous phase was transferred to a fresh tube. DNA was then precipitated by the addition of 0.7 vols 2-propanol and the precipitate was washed twice with $70 \%(\mathrm{v} / \mathrm{v})$ ethanol. After drying it was dissolved in an appropriate volume of TE buffer containing $0.01 \%(\mathrm{v} /$ v) RNase A solution $\left(10 \mathrm{mg} \mathrm{ml}^{-1}\right)$.

Determination of 165 rRNA gene sequence. Amplification of 16S rRNA genes was done by PCR using Taq DNA-polymerase (Invitrogen) and the primers $27 \mathrm{f}\left(5^{\prime}\right.$-GAGTTTGATCCTGGCTCAG$\left.3^{\prime}\right)$ and $1525 \mathrm{r}$ (5'-AGAAAGGAGGTGATCCAGCC-3'). Purification of the PCR product was carried out as described previously (Rainey et al., 1996). The purified 16S rRNA gene was then directly sequenced using the following primers: $27 \mathrm{f}$ (5'-GAGTTTGATCCTGGCTCAG- $\left.3^{\prime}\right), \quad 343 \mathrm{r}$ (5'-CTGCTGCCTCCCGTA- $\left.3^{\prime}\right)$, 357f (5' -TACGGGAGGCAGCAG-3'), 519r [5'-G(T/A)ATTACCGCGGC(T/G)GCTG-3'], 536f [5'-CAGC(C/A)GCCGCGGTAAT(T/ A)C-3'], 803f (5'-ATTAGATACCCTGGTAG-3'), 907r (5'-CCGTCAATTCATTTGAGTTT-3'), $1114 \mathrm{f}$ ( $5^{\prime}$-GCAACGAGCGCAACCC-3'), $1385 \mathrm{r} \quad\left[5^{\prime}\right.$-CGGTGTGT(A/G)CAAGGCCC-3'] and 1525r (5'AGAAAGGAGGTGATCCAGCC-3') applying the Big Dye 3.1 kit and a 3730 DNA capillary sequence analyser (Applied Biosystems). Sequences were aligned manually with published sequences from representative actinomycetes obtained from EMBL. BLASTN was used to determine the percentage of identical nucleotides to 16S rRNA gene sequences in the GenBank database. Phylogenetic trees were constructed by applying CLUSTAL $\mathrm{X}$ software (www-igbmc.ustrasbg.fr/BioInfo/; Thompson et al., 1997) using the neighbourjoining method (Saitou \& Nei, 1987) and were visualized by NJPLOT (ftp://pbil.univ-lyon1.fr/pub/mol_phylogeny/njplot; Perrière \& Gouy, 1996).
Determination of percentage mineralization. Evidence for biodegradation of the poly(cis-1,4-isoprene) and poly(trans-1,4-isoprene) hydrocarbon chains to $\mathrm{CO}_{2}$ was obtained by determination of respiratory $\mathrm{CO}_{2}$ released during cultivation of cells in the presence of polyisoprene as sole carbon source. Determination was carried out in tightly closed Erlenmeyer flasks by using the property of $\mathrm{Ba}(\mathrm{OH})_{2}$ to precipitate $\mathrm{CO}_{2}$ as $\mathrm{BaCO}_{3}$. The flasks, containing $100 \mathrm{ml}$ MSM medium, $0.6 \%$ milled poly(cis-1,4-isoprene) or poly (trans-1,4-isoprene), and a test tube, containing $15 \mathrm{ml}$ of a $0.2 \mathrm{M}$ $\mathrm{Ba}(\mathrm{OH})_{2}$ solution, were inoculated with 25 or $40 \mathrm{mg}$ cells (fresh wt) of a culture grown for $48 \mathrm{~h}$. At each measuring point, the flasks were aerated, and the test tubes were replaced by new tubes containing fresh $\mathrm{Ba}(\mathrm{OH})_{2}$ solution. Consumption of $\mathrm{HCl}$ for precipitation of $\mathrm{CO}_{3}^{2-}$ as $\mathrm{BaCO}_{3}$ was determined for each period by titration with $0.1 \mathrm{M} \mathrm{HCl}$ according to the following equation, yielding the percentage mineralization.

Mineralization $\left(\% \mathrm{CO}_{2}\right)=$

Required amount of $\mathrm{HCl}(\mathrm{ml}) \times 0.1$

$\mathrm{C}$ content of amount of poly(1,4-isoprene) applied $(\mathrm{mmol}) \times 2$

As indicator, phenolphthalein was added (20 $\mu \mathrm{l}$ of a $1 \%$, w/v, solution in 2-propanol) and the end point of titration was determined by alteration of the colour from magenta to uncoloured. A noninoculated Erlenmeyer flask was handled in the same way as control.

Scanning electron microscopy (SEM). Deterioration of samples of poly(cis-1,4-isoprene) and poly(trans-1,4-isoprene) by selected strains was verified by SEM. A sample $(40 \mathrm{ml})$ of a $1 \%$ solution of poly(trans-1,4-isoprene) in chloroform was placed into a glass Petri dish to obtain a thin polymer film after evaporation of the solvent. The film was then cut into pieces. Poly(cis-1,4-isoprene) was applied as cubic pieces with a side length of about $1 \mathrm{~cm}$. MSM cultures (200 ml) containing $1 \mathrm{~g}$ milled GP plus thin GP squares or $1 \mathrm{~g}$ milled poly(cis-1,4-isoprene) plus the cubes of poly(cis-1,4-isoprene) were inoculated with $70 \mathrm{mg}$ cell fresh weight of the respective strain grown for $48 \mathrm{~h}$ in St-I medium. The polymer pieces were withdrawn from their culture vessel after the incubation periods indicated in the text and were then washed with distilled water or used directly for SEM. Samples were gold-sputtered with an Emitech vacuum sputter device K550x (Ashford) and examined with a Hitachi S$3000 \mathrm{~N}$ scanning electron microscope at $20 \mathrm{kV}$ under high vacuum conditions. Micrographs were recorded digitally.

\section{RESULTS}

\section{Isolation of GP-degrading bacterial strains}

At the beginning we undertook several unsuccessful attempts to enrich GP-degrading bacteria from various soil samples, streets, sewage sludge and other places. We then used soil samples taken from the neighbourhood of GP-producing plants, expecting that in decaying plant material GP-degrading bacteria would naturally be enriched. In total, more than 100 samples were taken from different habitats to start enrichment and isolation of GP-degrading bacteria.

Numerous enrichment cultures yielded only 13 poly(trans1,4-isoprene)-degrading strains in total. Some strains, which were isolated from different enrichment cultures but inoculated with the same environmental sample, turned 
out to be identical, as revealed by $16 \mathrm{~S}$ rRNA gene sequencing. Thus, only six strains, differing in their $16 \mathrm{~S}$ rRNA gene sequences, were obtained and subsequently characterized. Five of these different strains were isolated from cultures inoculated with samples received from $C$. utilis populations in the Amazon rainforest in Brazil, and only one strain was isolated from a culture inoculated with a soil sample from an autochthonous E. europaeus population in Germany (for details, see Table 1). No bacterial strains capable of GP degradation could be isolated from samples taken from autochthonous E. europaeus populations located near the villages Wustrow, Trochel, Freude and Bleckede (Germany), from a wastewater treatment plant (Münster, Germany), from a composting plant (Münster, Germany) and from more than 30 samples taken from unassigned locations in the Amazon rainforest in Brazil. All newly isolated bacterial strains colonized the surface of the GP grains in liquid cultures (data not shown). Later it was shown that the isolates grew adhesively on poly (cis-1,4-isoprene) particles as has been described for species of Gordonia and Nocardia (Arenskötter et al., 2004; Ibrahim et al., 2006). These strains exhibited no clear zone formation when cultivated on overlay agar plates prepared from GP or NR latex.

\section{Taxonomic classification}

In liquid MSM cultures containing GP as sole source of carbon and energy, all strains exhibited coccoid growth, and strains WE30, L1b and SH22a also formed mycelia on solid complex St-I or Caso medium. Growth was clearly reduced at temperatures above $30^{\circ} \mathrm{C}$ and no growth was observed at temperatures higher than $37^{\circ} \mathrm{C}$. All strains were Grampositive and non-motile; no spores could be detected. Oxidase and LAAP tests were negative for all strains, but the catalase test demonstrated enzyme activity.

The sequences of complete 16S rRNA genes were determined as described in Methods to characterize the taxonomic position of the novel isolates in more detail. The new sequences were aligned with sequences deposited in GenBank to determine closely related species. The $16 \mathrm{~S}$ rRNA gene sequence of $N$. takedensis WE30 shared highest similarity $(99.9 \%)$ with that of Nocardia takedensis DSM $44801^{\mathrm{T}}$ which was previously isolated from moat sediment and activated sludge (Yamamura et al., 2005). Isolate WE30 is therefore referred to as $N$. takedensis WE30. The $16 \mathrm{~S}$ rRNA gene sequences of the isolates L1b, SH22a, SEI2b and SEII5a exhibited highest similarities (99.8, 98.9, 98.7 and 99.5\%, respectively) to that of Nocardia nova DSM $44481^{\mathrm{T}}$ (Wallace et al., 1991). These strains are therefore referred to as N. nova strains L1b, SH22a, SEI2b and SEII5a, respectively. The 16S rRNA gene sequence of strain SM1 shared highest similarities $(99.3 \%)$ with that of Nocardia jiangxiensis DSM $17684^{\mathrm{T}}$ (Cui et al., 2005). This isolate is therefore referred to as $N$. jiangxiensis SM1. The phylogenetic tree shown in Fig. 1 illustrates the relationship between the novel isolates to all validly described type strains of the genus Nocardia. Since $16 \mathrm{~S}$ rRNA analysis identified N. takedensis DSM $44801^{\mathrm{T}}$ as the type strain with the closest relationship to N. takedensis WE30, this strain was also investigated for its ability to degrade GP.

\section{Quantification of poly(trans-1,4-isoprene) and poly(cis-1,4-isoprene) degradation}

The capability of the newly isolated bacteria to utilize both isomers of poly(1,4-isoprene) as a carbon source had only been detected macroscopically up to this point. Thus, this property required verification by determining the respiratory evolution of $\mathrm{CO}_{2}$ during growth on ground material of the respective polymer. Since GP is a solid and waterinsoluble material, only the surface of poly(trans-1,4isoprene) is expected to be exposed to microbial attack. Consequently, an increase in the available surface of the polymer should enhance the degradation rate, even if the total weight of the applied material is kept constant. The polymer was cryomilled to examine the effect of the surface area on the degradation rates of poly(trans-1,4-isoprene). The granules thus obtained were then sieved applying a Retsch AS 200 basic sieve shaker to obtain granule fractions with defined grain sizes of 125-250, 250-500, 500-710, $710-1000$ and $1250-1400 \mu \mathrm{m}$, respectively. For each grain, a $100 \mathrm{ml}$ MSM culture containing $0.6 \mathrm{~g}$ of the respective granule fraction was inoculated with $40 \mathrm{mg}$ fresh cell weight of $N$. takedensis WE30, and mineralization was measured comparatively to observe the dependence of degradation on the available GP surface. Fig. 2(a) clearly illustrates a correlation between the size of the supplied granules and the extent of GP degradation by N. takedensis WE30. If smaller particles were provided, mineralization proceeded more rapidly when compared to cultures with larger granules. In cultures with GP grains of $125-250 \mu \mathrm{m}, 40 \%$ of the substrate was metabolized to $\mathrm{CO}_{2}$ within 78 days, while only $25 \%$ of the poly(trans-1,4-isoprene) granules of $1250-1400 \mu \mathrm{m}$ was mineralized in the same period by $N$. takedensis WE30. This indicated that only the surface of the material is accessible to microbial attack, as is usually the case with solid biodegradable materials.

The capability of the newly isolated Nocardia strains and of $N$. takedensis DSM $44801^{\mathrm{T}}$ to utilize both isomers of poly(1,4-isoprene) as carbon source was then compared in mineralization experiments. The highest mineralization values of poly(trans-1,4-isoprene) were obtained with $N$. nova strains L1b and SEI2b, and with N. takedensis WE30. After 80 days incubation, these strains had metabolized about $42-54 \%$ of the supplied GP to $\mathrm{CO}_{2}$ (Fig. 2b). The type strain of $N$. takedensis mineralized only about $20 \%$ of the GP during the same period, and the slowest rate of degradation was observed with $N$. jiangxiensis SM1 which released only about $3 \%$ of the poly(trans-1,4-isoprene) as $\mathrm{CO}_{2}$ (Fig. 2b). Mineralization of poly(trans-1,4-isoprene) by cultures of $G$. polyisoprenivorans $\mathrm{VH} 2$ and $R$. opacus PD630 was also measured as controls. G. polyisoprenivorans $\mathrm{VH} 2$ has been characterized as a potent degrader of poly (cis1,4-isoprene) by Linos \& Steinbüchel (1998), but was incapable of degrading poly(trans-1,4-isoprene) (Fig. 2b). Also, R. opacus PD630 did not degrade poly(trans-1, 


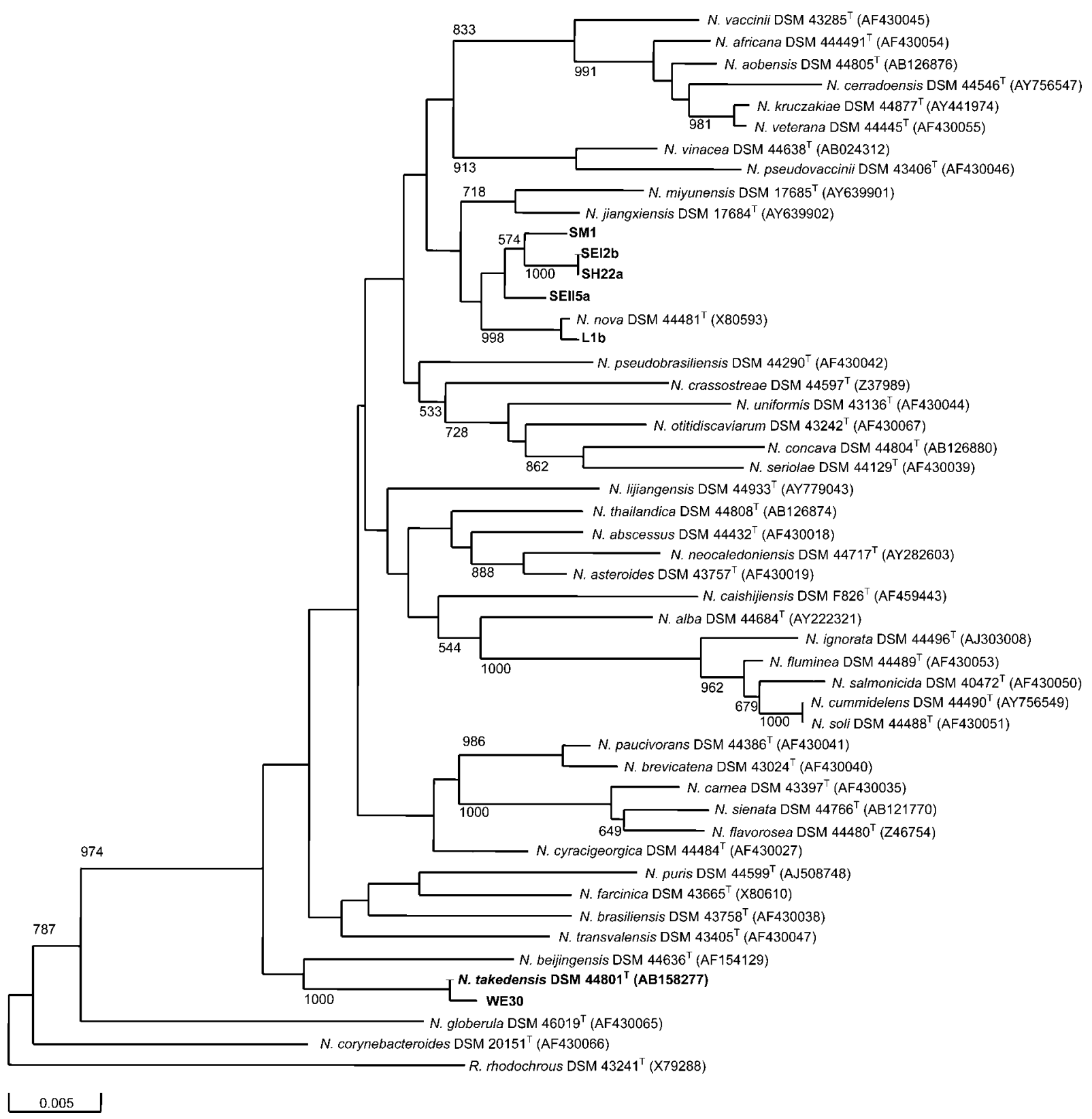

Fig. 1. Neighbour-joining tree based on nearly complete $16 \mathrm{~S}$ rRNA gene sequences (1346 bp) of all type strains of validly described Nocardia species and of the novel bacterial isolates capable of degrading poly(trans-1,4-isoprene). Numbers at nodes indicate the level of bootstrap support based on neighbour-joining analysis of 1000 resampled datasets; only values above $50 \%$ are given. Bar, 0.005 substitutions per nucleotide position.

4-isoprene) as indicated by mineralization studies (Fig. 2b). In addition, no growth on poly (trans-1,4-isoprene) could be detected macroscopically for these two bacteria.

In the past, numerous bacterial strains have been described that degrade both synthetic poly(cis-1,4-isoprene) and NR (Jendrossek et al., 1997; for review, see Rose \& Steinbüchel, 2005); however, these strains do not degrade the trans isomer GP as revealed from a laboratory screening of several of them (unpublished data). In this study we decided to clarify if the novel GP-degrading strains and N. takedensis DSM $44801^{\mathrm{T}}$ also are capable of degrading poly(cis-1,4isoprene). Therefore, all six poly(trans-1,4-isoprene)degrading strains and $N$. takedensis DSM $44801^{\mathrm{T}}$ were tested for their ability to utilize poly(cis-1,4-isoprene) as a source for carbon and energy, and degradation was compared by mineralization experiments to that of $G$. polyisoprenivorans VH2 (Fig. 2c). All the novel Nocardia strains and $N$. takedensis DSM $44801^{\mathrm{T}}$ were indeed able to utilize poly(cis-1,4-isoprene) very efficiently and metabolized 

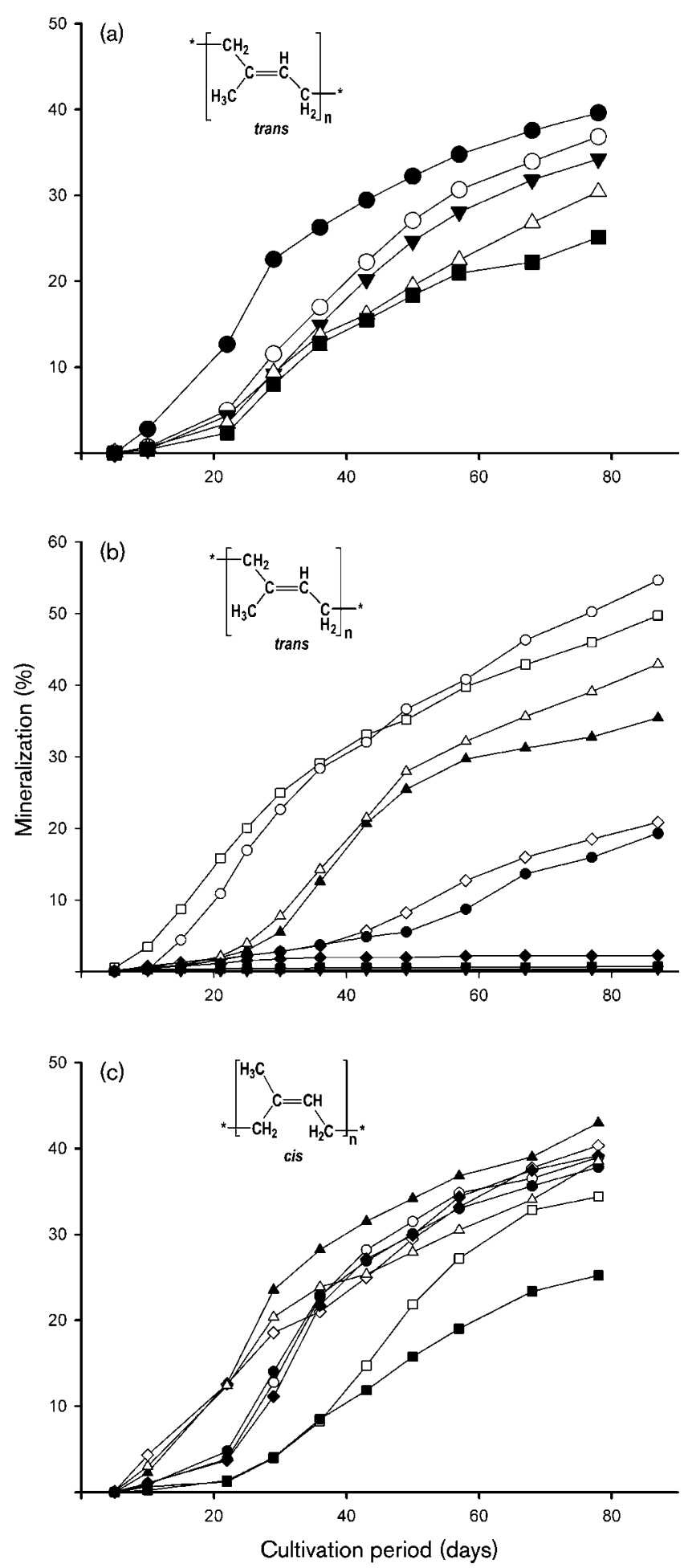

this polymer for the most part even more rapidly than $G$. polyisoprenivorans $\mathrm{VH} 2$. The highest degree of mineralization after 78 days was obtained with $N$. nova SH22a (43\%). $N$. nova L1b metabolized only $34 \%$ of the poly(cis-1,4isoprene) to $\mathrm{CO}_{2}$, but was also more efficient than $G$. polyisoprenivorans VH2 (25\%). However, the values for mineralization of poly(cis-1,4-isoprene) by the novel
Fig. 2. Percentage mineralization during growth of bacteria on polyisoprenoides. (a) Effect of GP granule size on mineralization. Cultures $(100 \mathrm{ml})$ in mineral salts medium containing $0.6 \%(\mathrm{w} / \mathrm{v})$ synthetic poly(trans-1,4-isoprene) with a defined granule size ( $\bullet$, 125-250; $\bigcirc, 250-500 ; \nabla, 500-710 ; \triangle, 710-1000 ; \mathbf{\square}$, 1250-1400 $\mu \mathrm{m}$ ) were inoculated with $40 \mathrm{mg}$ cell fresh weight of isolate WE30. (b) Mineralization of GP by novel GP-degrading strains. Cultures $(100 \mathrm{ml})$ in mineral salts medium containing $0.6 \%(\mathrm{w} / \mathrm{v})$ synthetic poly(trans-1,4-isoprene) (granule size, 250-500 $\mu \mathrm{m}$ ) were inoculated with $25 \mathrm{mg}$ fresh cell weight of the respective strains $(\square, \mathrm{L} 1 \mathrm{~b} ; \diamond, N$. takedensis; $\bigcirc, \mathrm{SEI} 2 \mathrm{~b} ; \boldsymbol{\Delta}$, $\mathrm{SH} 22 \mathrm{a} ; \bullet$ SEll5a; $\triangle$, WE30; $\diamond$ SM1), or of G. polyisoprenivorans $\mathrm{VH} 2(\boldsymbol{\nabla})$ or $R$. opacus PD630 ( $)$ as negative controls. (c) Mineralization of poly(cis-1,4-isoprene) rubber by novel GPdegrading strains and by the NR-degrading strain G. polyisoprenivorans $\mathrm{VH} 2$. Cultures $(100 \mathrm{ml})$ in mineral salts medium containing $0.6 \%(w / v)$ synthetic poly(cis-1,4-isoprene) rubber (granule size, 250-500 $\mu \mathrm{m}$ ) were inoculated with $40 \mathrm{mg}$ cell fresh weight of the respective strains $(\square, \mathrm{L} 1 \mathrm{~b} ; \diamond, N$. takedensis; $\bigcirc, \mathrm{SEI} 2 \mathrm{~b} ; \diamond$, $\mathrm{SM} 1 ; \boldsymbol{\Delta}, \mathrm{SH} 22 \mathrm{a} ; \bullet$, SEll5a; $\triangle$, WE30; $\mathbf{0}$, G. polyisoprenivorans). All values represent the arithmetic mean of two individual cultures. The deviation from the arithmetic mean was $11.8 \%$ for all measurements with an SD of $18.7 \%$.

GP-degrading strains diverged to a lesser extent than observed for their mineralization of the trans isomer.

\section{Visualization of GP and rubber degradation by SEM}

Films of GP and cubes of synthetic poly(cis-1,4-isoprene) were incubated for 1,3 and 5 weeks with cells of $N$. takedensis WE30 and N. nova L1b, and were then examined by SEM to observe the degradation of poly(trans-1,4isoprene) and poly(cis-1,4-isoprene) visually in a chronological sequence (Figs 3 and 4). GP films incubated with cells of $N$. takedensis WE30 exhibited a few cavities with diameters of approximately $10 \mu \mathrm{m}$ after only 1 week (Fig. 3a). After 3 weeks incubation, approximately 20 cavities $\mathrm{mm}^{-2}$ with diameters of about $30 \mu \mathrm{m}$ were observed (Fig. 3b). After 5 weeks incubation, the surfaces of the GP films had almost totally deteriorated; cavities were confluent and separated cavities could hardly be distinguished (Fig. 3c); only a few holes with diameters of about $60 \mu \mathrm{m}$ permeating the entire GP film were visible. This progression was also observed in cultures of N. nova L1b. In the samples withdrawn after 1 week incubation, signs of degradation were hardly visible by SEM (Fig. 3e), whereas after 3 weeks incubation, the material exhibited approximately 15 cavities $\mathrm{mm}^{-2}$ with diameters of about $20 \mu \mathrm{m}$ (Fig. 3f). The numbers and diameters of the cavities continued to increase, and after 5 weeks incubation with $N$. nova L1b approximately 50 holes $\mathrm{mm}^{-2}$ with diameters of about $40 \mu \mathrm{m}$ were observed (Fig. 3g). In contrast, GP films of a non-inoculated control exhibited no evidence of deterioration (Fig. 3d). Consequently, the appearance of cavities was clearly due to microbial attack of poly(trans-1,4-isoprene) by N. takedensis WE30 and N. nova L1b. In addition, the GP films exhibited 

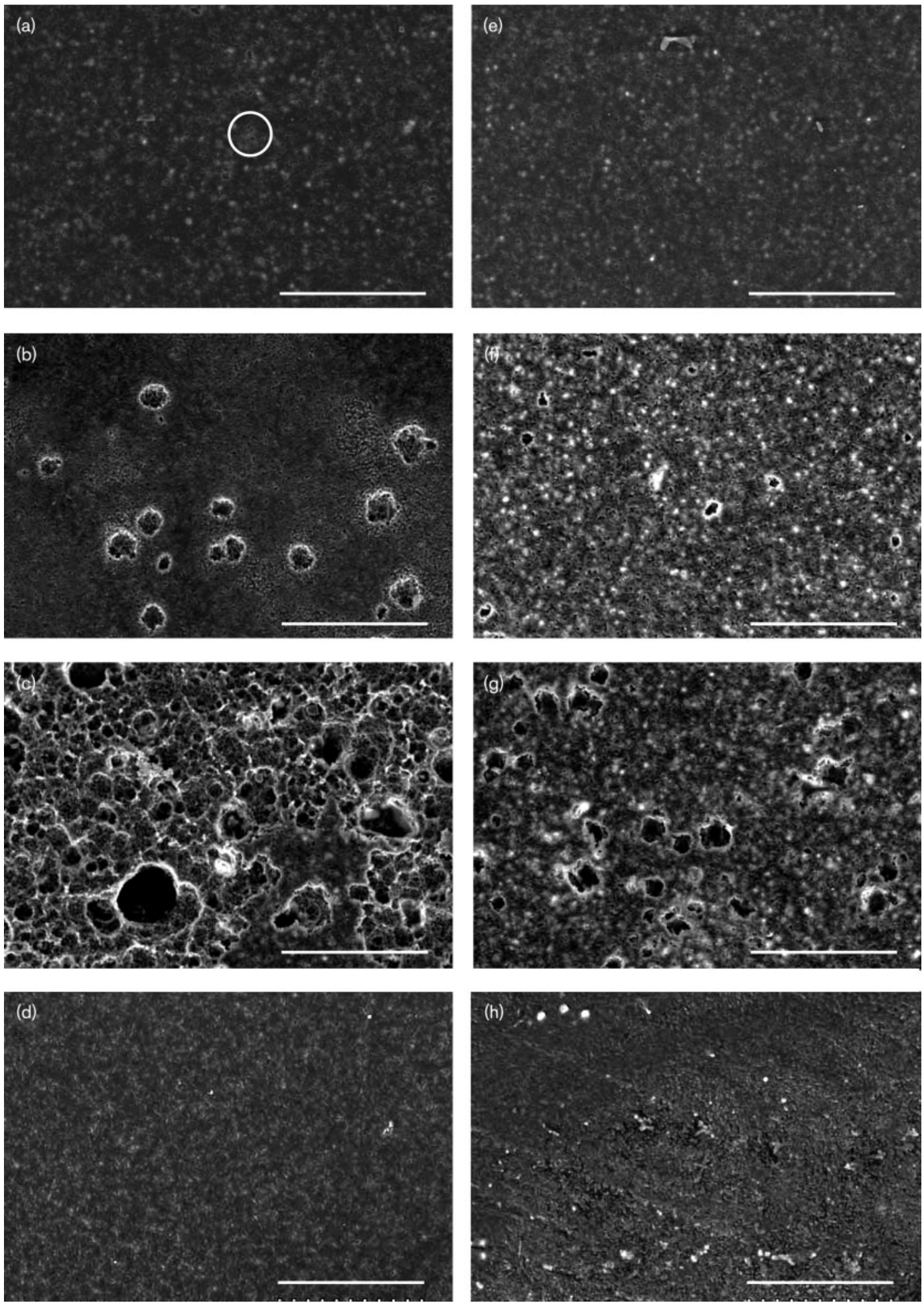

Fig. 3. Scanning electron micrographs of GP films after incubation with micro-organisms. GP films were incubated with cells of $N$. takedensis WE30 (a-c) and N. nova L1b (e-g). Films were incubated for $1(\mathrm{a}, \mathrm{e}), 3(\mathrm{~b}, \mathrm{f})$ and 5 weeks (c, g). (h) Surface of a GP film after 5 weeks incubation in the presence of G. polyisoprenivorans. (d) Surface of a GP film after 5 weeks incubation in a non-inoculated sterile control. The circle in (a) highlights a cavity which is difficult to recognize in this stage. Bars, $200 \mu \mathrm{m}$. 

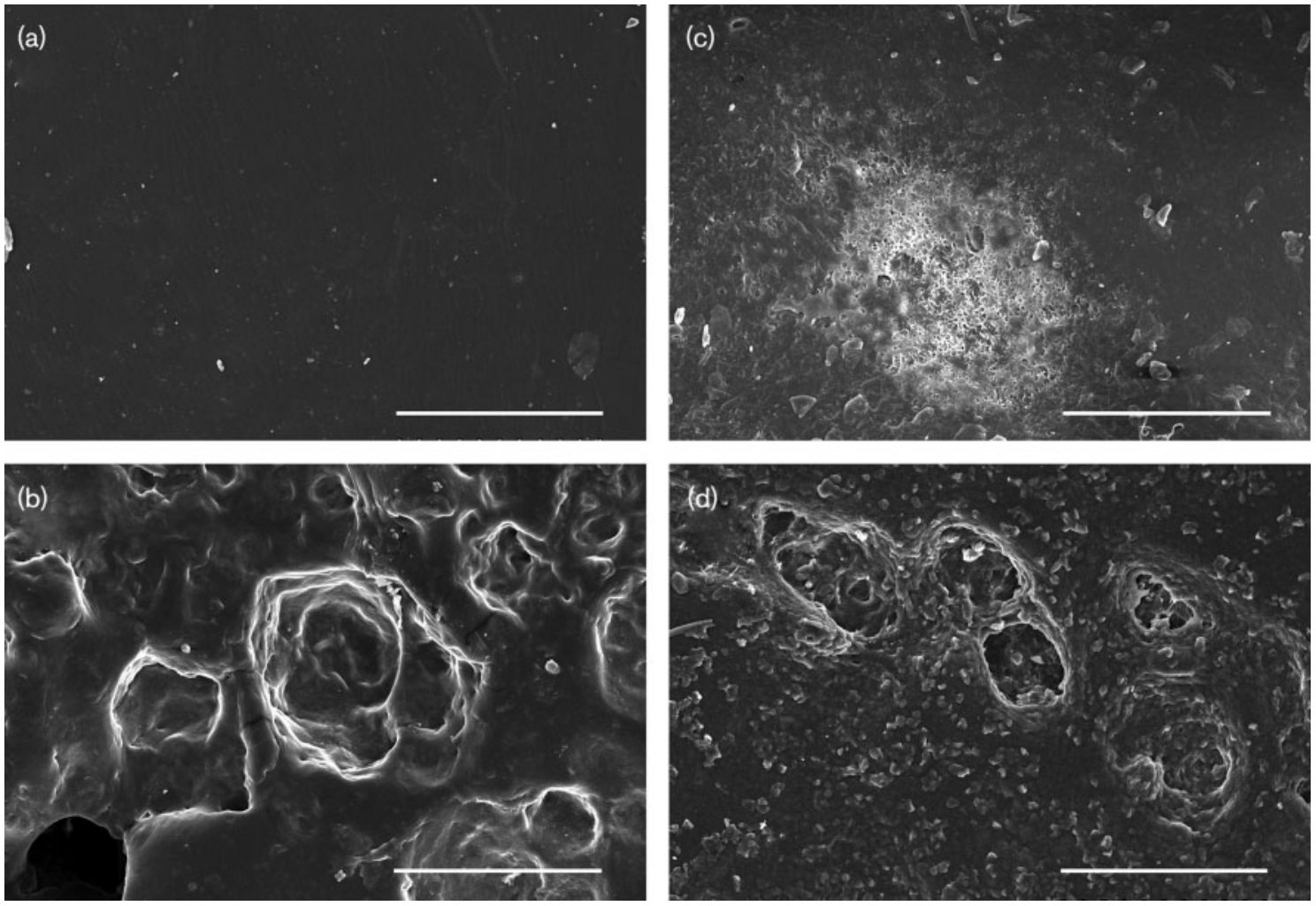

Fig. 4. Scanning electron micrographs of the surface of poly(cis-1,4-isoprene) particles after incubation with $G$. polyisoprenivorans VH2 (b), N. takedensis WE30 (c) and N. nova L1b (d) for 5 weeks. (a) Surface of poly(cis-1,4isoprene) after 5 weeks incubation under the same conditions in the absence of bacterial cells. Bars, $200 \mu \mathrm{m}$.

no cavities or other signs of degradation when incubated with cells of G. polyisoprenivorans VH2 (Fig. 3h), thus confirming the inability of this poly(cis-1,4-isoprene)degrading bacterium to degrade the trans isomer.

The surfaces of the poly(cis-1,4-isoprene) cubes, as imaged by SEM after an incubation period of 5 weeks, are presented in Fig. 4(a-d). In the absence of bacterial cells (uninoculated control), the surface was not modified (Fig. 4a). In contrast, cells of $G$. polyisoprenivorans $\mathrm{VH} 2$ caused remarkable deterioration as indicated by the appearance of large cavities in the rubber (Fig. 4b), as already shown for this strain (Linos et al., 2000). The surfaces of the rubber particles were attacked to a similar extent by N. takedensis WE30 (Fig. 4c) and $N$. nova L1b (Fig. 4d), thereby confirming that these strains are also potent NR-degrading bacteria.

However, despite the adhesive growth of all the isolates on GP and poly(cis-1,4-isoprene), cells were never visible in the scanning electron micrographs. This is probably due to the procedure of sample preparation and due to only very weak adhesion of the cells to the polymer materials.

\section{DISCUSSION}

All previous efforts have failed to identify micro-organisms capable of degrading poly(trans-1,4-isoprene), also referred to as GP. Vague hints for the biodegradability of poly(trans1,4-isoprene) were obtained by fermentation of Eucommia leaves containing GP; however, it turned out that chemically pure poly(trans-1,4-isoprene) was not degraded (Kupletskaya et al., 1960). Obviously, the growth of the micro-organisms in this case was only due to other compounds present in the leaves. Additionally, several bacterial strains well known as poly(cis-1,4-isoprene)degraders cannot utilize the trans isomer of polyisoprene (unpublished data), and even purified RoxA, which is responsible for poly(cis-1,4-isoprene) cleavage by Xanthomonas sp. 35Y, was shown to be incapable of cleaving poly(trans-1,4-isoprene) in vitro (Braaz et al., 2004). However, GP as a natural compound ought to be biodegradable (Steinbüchel, 2005). This assumption led us to investigate if poly(trans-1,4-isoprene)-degrading bacterial strains could be isolated from the habitats of plants synthesizing GP. This is the first report of micro-organisms which are unequivocally capable of degrading GP.

Although more than 100 environmental samples were investigated, bacterial growth could only be detected macroscopically in 6 enrichment cultures, each yielding one strain in axenic culture metabolizing poly(trans-1,4isoprene). It is possible that cultivatable GP-degrading bacteria are endemic and occur only in habitats where 
poly (trans-1,4-isoprene) is present due to decaying material from plants synthesizing GP. GP-utilizing bacteria are obviously not ubiquitously distributed in nature, otherwise previous investigations should have succeeded in isolating poly(trans-1,4-isoprene)-degrading strains.

Interestingly, all strains isolated in this study were taxonomically assigned to the genus Nocardia based on their $16 \mathrm{~S}$ rRNA gene sequences. Based on these data the isolates L1b, SH22a, SEI2b and SEII5a were assigned as strains of N. nova, isolate WE30 as a strain of $N$. takedensis and isolate SM1 as a strain of N. jiangxiensis. These GPdegrading bacteria belong therefore to the mycolic-acidcontaining Actinobacteria [Corynebacterium, Mycobacterium, Nocardia (CMN) group]. All GP-degrading bacteria were also able to degrade NR. In this regard they behaved like most rubber-degrading bacteria representing the socalled 'adhesively growing group' of rubber degraders (Linos et al., 2000). In contrast to several NR-degrading streptomycetes, these GP-degrading bacteria do not produce translucent haloes on agar plates containing emulsified NR latex of Hevea brasiliensis or latex from the South American tree Couma utilis that contains both poly(trans1,4-isoprene) and poly(cis-1,4-isoprene). Instead, they grew adhesively on both isomers if incubated in liquid cultures like all rubber-degrading species of the genus Gordonia do on NR (Arenskötter et al., 2004).

Mineralization experiments clearly revealed that the GPdegrading isolates, as well as $N$. takedensis DSM $44801^{\mathrm{T}}$, metabolized synthetic poly(trans-1,4-isoprene), although they exhibited marked differences regarding the percentage of mineralization. Mineralization studies and SEM clearly revealed that the poly(cis-1,4-isoprene)-degrading bacterium G. polyisoprenivorans $\mathrm{VH} 2$ did not exhibit any detectable degradation of poly(trans-1,4-isoprene), and nor did the negative control $R$. opacus PD630. This confirmed previous observations that bacteria capable of degrading poly(cis-1,4-isoprene) do not degrade the trans isomer. In contrast, all poly(trans-1,4-isoprene)-degrading bacteria isolated described in this study and N. takedensis DSM $44801^{\mathrm{T}}$ were also able to degrade poly(cis-1,4isoprene). Therefore, the ability to degrade GP always seems to occur in combination with the capability to degrade NR. In general, biodegradation of both the $c i s$ and trans isomers is a similarly slow process. It will be interesting to determine if GP-degrading bacteria possess one unspecific enzyme system for degradation of both isomers of polyisoprenoides, or if two separate enzyme systems exist in these bacteria: one responsible for degradation of the trans isomer and the other for the cis isomer. In the latter case, it should be possible to isolate bacteria capable of utilizing only poly(trans-1,4-isoprene) but not poly(cis-1,4-isoprene). Previous observations that biodegradation of poly(trans-1,4-isoprene) is a rare process are supported by the fact that none of the many poly(cis-1,4-isoprene)degrading bacteria isolated so far is able to degrade poly(trans-1,4-isoprene).
All newly isolated strains capable of degrading poly(trans1,4-isoprene) colonized the surface of the water-insoluble polymer during growth in liquid cultures, as has been described for taxonomically related bacteria that degrade the cis isomer. Therefore, the surface area of GP particles or the surface to volume ratio affect the percentage of mineralization since only the exposed surface is supposed to be accessible to the bacteria and their enzymes. This was clearly demonstrated with granule fractions of GP varying in grain size; the highest percentage of mineralization was observed with particles of the smallest grain size $(125-250 \mu \mathrm{m})$. Therefore, to obtain reliable and comparable quantitative data on the degradation of poly(trans-1,4-isoprene) or on degradation by different micro-organisms, the granule size should be kept within a defined and narrow range.

\section{ACKNOWLEDGEMENTS}

The authors are indebted to Dr Dietrich Hoffmann (Niedersächsische Forstversuchsanstalt, Escherode, Germany) for reporting autochthonous Eunonymus europaeus populations in Germany.

\section{REFERENCES}

Arenskötter, M., Bröker, D. \& Steinbüchel, A. (2004). Biology of the metabolically diverse genus Gordonia. Appl Environ Microbiol 70, 3195-3204.

Arvanitoyannis, I., Kolokuris, I., Nakayama, A. \& Aiba, S. (1998). Preparation and study of novel biodegradable blends based on gelatinized starch and 1,4-transpolyisoprene (gutta percha) for food packaging or biomedical applications. Carbohydr Polym 34, 291-302. Backhaus, R. A. (1985). Rubber formation in plants. Israel J Bot 34, 283-293.

Banh, Q., Arenskötter, M. \& Steinbüchel, A. (2005). Establishment of Tn5096-based transposon mutagenesis in Gordonia polyisoprenivorans. Appl Environ Microbiol 71, 5077-5084.

Braaz, R., Fischer, P. \& Jendrossek, D. (2004). Novel type of hemedependent oxygenase catalyzes oxidative cleavage of rubber (poly-cis1,4-isoprene). Appl Environ Microbiol 70, 7388-7395.

Cui, Q., Wang, L., Huang, Y., Liu, Z. \& Goodfellow, M. (2005). Nocardia jiangxiensis sp. nov. and Nocardia miyunensis sp. nov., isolated from acidic soils. Int J Syst Evol Microbiol 55, 1921-1925.

Enoki, M., Doi, Y. \& Iwata, T. (2003). Oxidative degradation of trans1,4-polyisoprene cast films and single crystals by enzyme-mediator systems. Macromol Biosci 3, 668-674.

Gerhardt, P., Murray, R. G. E., Wood, W. A. \& Krieg, N. R. (1994). Methods for General and Molecular Bacteriology. Washington, DC: American Society for Microbiology.

Ibrahim, E. M. A., Arenskötter, M., Luftmann, H. \& Steinbüchel, A. (2006). Identification of poly(cis-1,4-isoprene) degradation intermediates during growth of moderately thermophilic Actinomycetes on rubber and cloning of a functional $l c p$ homologue from Nocardia farcinica strain E1. Appl Environ Microbiol 72, 3375-3382.

Jendrossek, D., Tomassi, G. \& Kroppenstedt, R. (1997). Bacterial degradation of natural rubber: a privilege of actinomycetes? FEMS Microbiol Lett 150, 179-188.

Kupletskaya, M. B., Kuznetsova, V. M. \& Zhukova, S. V. (1960). Microbiological maceration of Eucommia leaves. III. Disintegration of gutta and resins in the process of fermentation of the leaves. Mikrobiologiia 29, 259-265 (in Russian). 
Linos, A. \& Steinbüchel, A. (1998). Microbial degradation of natural and synthetic rubbers by novel bacteria belonging to the genus Gordona. Kautsch Gummi Kunstst 51, 496-499.

Linos, A., Berekaa, M. M., Reichelt, R., Keller, U., Schmitt, J., Flemming, H. C., Kroppenstedt, R. M. \& Steinbüchel, A. (2000). Biodegradation of cis-1,4-polyisoprene rubbers by distinct actinomycetes: microbial strategies and detailed surface analysis. Appl Environ Microbiol 66, 1639-1645.

Perrière, G. \& Gouy, M. (1996). WWW-Query: an on-line retrieval system for biological sequence banks. Biochimie 78, 364-369.

Rainey, F. A., Ward-Rainey, N., Kroppenstedt, R. M. \& Stackebrandt, E. (1996). The genus Nocardiopsis represents a phylogenetically coherent taxon and a distinct actinomycete lineage: proposal of Nocardiopsaceae fam. nov. Int J Syst Bacteriol 46, 1088-1092.

Rose, K. \& Steinbüchel, A. (2005). Biodegradation of natural rubber and related compounds: recent insights into a hardly understood catabolic capability of microorganisms. Appl Environ Microbiol 71, 2803-2812.

Rose, K., Tenberge, K. B. \& Steinbüchel, A. (2005). Identification and characterization of genes from Streptomyces sp. strain K30 responsible for clear zone formation on natural rubber latex and poly(cis-1,4-isoprene) rubber degradation. Biomacromolecules 6, $180-188$.
Saitou, N. \& Nei, M. (1987). The neighbour-joining method: a new method for reconstructing phylogenetic trees. Mol Biol Evol 4, 406-425.

Schlegel, H. G., Kaltwasser, H. \& Gottschalk, G. (1961). Ein Submersverfahren zur Kultur wasserstoffoxidierender Bakterien: Wachstumsphysiologische Untersuchungen. Arch Mikrobiol 38, 209-222.

Söhngen, N. L. \& Fol, J. G. (1914). Die Zersetzung des Kautschuks durch Mikroben. Zentralbl Bakteriol Parasitenkd Infektionskr 40, 87-98.

Steinbüchel, A. (2005). Non-biodegradable biopolymers from renewable resources: perspectives and impacts. Curr Opin Biotechnol 16, 607-613.

Thompson, J. D., Gibson, T. J., Plewniak, F., Jeanmougin, F. \& Higgins, D. G. (1997). The CLUSTAL X windows interface: flexible strategies for multiple sequence alignment aided by quality analysis tools. Nucleic Acids Res 25, 4876-4882.

Wallace, R. J., Brown, B. A., Tsukamura, M., Brown, J. M. \& Onyi, G. O. (1991). Clinical and laboratory features of Nocardia nova. J Clin Microbiol 29, 2407-2411.

Yamamura, H., Hayakawa, M., Nakagawa, Y., Tamura, T., Kohno, T., Komatsu, F. \& limura, Y. (2005). Nocardia takedensis sp. nov., isolated from moat sediment and scumming activated sludge. Int J Syst Evol Microbiol 55, 433-436.

Edited by: J. D. Semrau 